\title{
TATTOO GANESA, TATU BAGI UMAT HINDU
}

\author{
Oleh: \\ I Gusti Ketut Widana \\ Fakultas Pendidikan Agama dan Seni \\ Universitas Hindu Indonesia \\ Denpasar \\ igustiketutwidana1805@gmail.com
}

\begin{abstract}
The influence of tourism for the majority of Balinese Hindus making the existence of Bali Island a center of national tourism development, even international. Added to the acceleration of the rate of modernization with the wave of globalization that is so powerful, whether or not it has entered and touched, even slowly but surely has eroded the established order of Bali's scene with all its changes. At least in terms of openness, Balinese people (Hindus) tend to be so easy to accept outside elements (foreign), almost without selection. The permissiveness or the letting go of what comes has made the Hindus so vulnerable to be affected, especially by the negative, destructive and counterproductive influences to the religiously defended values that are morally vested in the value of money. Like the commodification of the values of holiness or sacredness of the sacred symbol of Hindu like god Ganesha which by the tourism businessmen has made as Tattoo object with the human body media (male/ female) as a canvas, which is not uncommonly painted on the sensual organ. The Tattooo of Dewa Ganesha on the human body is actually a Tatu (wound) that slashed even sliced the heart, feelings and inner state of thhe Hindus, because the figure of Ganesha worshiped has been dumped, harassed and even tainted by sacredness solely for the taste of tourists for the benefit of material gain/ financial for the perpetrators of tourism.
\end{abstract}

Keywords: Tattoo, Ganesa, Hindu

\begin{abstract}
Abstrak
Pengaruh pariwisata bagi mayoritas masyarakat Baliyang beragama Hindu, membuat keberadaan Pulau Bali menjadi pusat pengembangan kepariwisataan nasional, bahkan internasional. Ditambah akselerasi laju modernisasi dengan gelombang globalisasinya yang begitu dahsyat, disadari ataupun tidak telah masuk dan menyentuh, bahkan perlahan tapi pasti sudah menggerus tatanan mapan ke-ajegan Bali dengan segala bentuk perubahannya. Setidaknya dalam hal keterbukaan, masyarakat Bali (umat Hindu) cenderung begitu mudah menerima unsur-unsur luar (asing), nyaris tanpa seleksi. Sikap permisif atau membiarkan begitu saja apa yang datang, membuat umat Hindu begitu rentan terpengaruh, terutama oleh hal-hal yang bersifat negatif, destruktif dan kontraproduktif terhadap kebertahanan nilai-nilai religius yang kian diberangus kepentingan meraup fulus (uang/ materi). Seperti terjadinya komodifikasi terhadap nilai-nilai kesucian atau kesakralan simbol suci Hindu Dewa Ganesa yang oleh kalangan pebisnis pariwisata dijadikan objek Tattoo dengan media tubuh manusia (laki/perempuan) sebagai kanvas, yang tidak jarang dilukis pada bagian organ sensual. Tattoo Dewa Ganesa pada tubuh manusia ini sejatinya merupakan Tatu (luka) yang menyayat bahkan mengiris hati, perasaan dan kebatinan umat Hindu, karena sosok Ganesa yang selama ini dipuja telah dicampakkan, dilecehkan bahkan dinodai kesucian/kesakralannya semata-
\end{abstract}


mata demi memenuhi selera wisatawan yang ujung-ujungnya untuk kepentingan meraih keuntungan material/finasnsial bagi pelaku pariwisata.

Kata kunci: Tattoo, Ganesa, Umat Hindu

\section{PENDAHULUAN}

Pelaksanaan yadnya dengan rangkaian upacara dan upakaranya melahirkan beraneka rupa, bentuk, jenis, peralatan, sarana, prasarana lainnya, lengkap dengan simbol-simbol yang disandang, beserta makna yang dikandung yang secara kasat mata memang lebih tampak sebagai benda hasil kreasi budaya (cipta, rasa, karsa) umat, namun ditinggikan derajat nilainya, sehingga tidak sekedar bernilai benda dengan gunanya tetapi juga bernilai simbolik.

Namun di tengah derasnya arus pariwisata global di Bali, dengan pengaruh materialisme dan kapitalismenya, sepertinya tidak ada lagi hal yang tidak bisa dijual demi alasan memajukan industri pariwisata yang telah dinobatkan sebagai pengumpul devisa terbesar setelah minyak bumi. Akhirnya, semua potensi kebudayaan ragawi (kebendaan) termasuk rohani (keagamaan) menjadi serba "bisa/ boleh" dikemas sebagai produk berlabel pariwisata. Pandangan inilah yang kemudian melahirkan pernyataan, bahwa di Bali sekarang ini umat Hindunya sudah menjadikan pariwisata sebagai "agama" zaman now berbasis "monbeytheisme". Suatu bentuk keyakinan (sebagian) masyarakat Bali yang memandang, hanya dengan pariwisatalah Bali bisa mencapai kesejahteraan fisikal, melalui pundi-pundi pendapatan (keuangan), meski harus menyeret hal-hal sakral-transendental ke ranah materialfinansial (Widana, 2012: 15).

Apalagi jika ditilik dari sisi kepentingan agama yang menjadi pondasi kekuatan spiritual Bali, bisa saja karena pariwisatalah Pulau Bali yang sakral (suci), dengan orang Bali (Hindu) yang berjiwa sosio-magis-religius justru menjadi ambisius mengejar keuntungan material-finansial. Akibat ambisi mengejar target devisa negara, meningkatkan pendapatan asli daerah, meraup keuntungan besar para pelaku pariwisata, akhirnya Pulau Bali tak ubahnya seperti "komoditi", sebagaimana layaknya barang dagangan untuk kemudian dijual bahkan tak jarang diobral. Termasuk yang kini menimpa sosok suci putra Dewa Siwa yaitu Dewa Ganesa, yang mau tidak mau harus mengalami degradasi nilai dalam bentuk desakralisasi atau profanisasi, dengan menjadikannya sebagai objek Tattoo pada media tubuh manusia, bisa laki dan perempuan, diantaranya dengan menempatkan gambarnya pada bagian organ sensual.

\section{PEMBAHASAN}

\subsection{Riwayat Dewa Ganesa}

\section{1) Kelahiran Dewa Ganesa}

Terdapat berbagai versi mengenai kelahiran Ganesa, namun kisah yang paling terkenal berasal dari kitab Siwapurana. Mitos-mitos dalam Purana memiliki ketidakpastian mengenai kelahirannya. Dia bisa saja diciptakan oleh Siwa, atau oleh Parwati, atau oleh Siwa dan Parwati, atau muncul secara misterius dan ditemukan oleh Siwa dan Parwati. Meski pada umumnya Ganesa terkenal sebagai putera dari Siwa dan Parwati.

Merujuk versi kitab Siwapurana dikisahkan, suatu ketika Parwati (istri Dewa Siwa) ingin mandi. Karena tidak ingin diganggu, ia menciptakan seorang anak laki-laki. Ia berpesan agar anak terssebut tidak mengizinkan siapapun masuk ke rumahnya selagi Dewi Parwati mandi dan hanya boleh melaksanakan perintah Dewi Parwati saja. Perintah itu dilaksanakan sang anak dengan baik. Alkisah ketika Dewa Siwa hendak masuk ke rumahnya, ia tidak dapat masuk karena dihadang oleh anak kecil yang menjaga rumahnya. Bocah tersebut melarangnya karena ia ingin melaksanakan perintah Parwati dengan baik. siwa menjelaskan, bahwa ia suami Parwati dan rumah yang dijaga si bocah adalah rumahnya juga. Namun sang bocah tidak mendengarkan perintah Siwa, sesuai dengan perintah ibunya untuk tidak mendengar perintah siapapun. Akhirnya Siwa kehabisan kesabarannya dan bertarung dengan anaknya sendiri. pertarungan amat sengit sampai akhirnya Siwa menggunakan Trisulanya dan memenggal kepala si bocah. 
Ketika Parwati selesai mandi, ia mendapati puteranya sudah tidak bernyawa. Ia marah kepada suaminya dan menuntut agar anaknya dihidupkan kembali. Siwa sadar akan perbuatannya dan ia menyanggupi permohonan istrinya. Atas saran Brahma, Siwa kemudian mengutus abdinya, yaitu para gana, untuk memenggal kepala makhluk apapun yang dilihatnya pertama kali yang menghadap ke utara. Ketika turun ke dunia, gana mendapati seekor gajah sedang menghadap utara. Kepala gajah itu pun dipenggal untuk menggantikan kepala Ganesa. Akhirnya Ganesa dihidupkan kembali oleh Dewa Siwa dan sejak itu diberi gelar Dewa Keselamatan (Satria, 2015 : 40-41).

\section{2) Penggambaran Dewa Ganesa}

Ganesa kadangkala digambarkan berdiri, menari, atau duduk. Ganesa adalah sosok Dewa berkepala gajah dengan perut buncit, dan memiliki empat lengan. Dia membawa patahan gadingnya dengan tangan kanan bawah dan membawa kudapan manis, yang ia comot dengan belalainya, pada tangan kiri bawah. Ganesa juga memegang sebuah kapak atau angkusa pada tangan sebelah atas dan sebuah jerat pada tangan atas lainnya.

Pada mulanya nama Ganesha adalah Ekadanta (satu gading), merujuk kepada gadingnya yang utuh hanya berjumlah satu, sedangkan yang lainnya patah. Ganesa juga digambarkan dengan perut buncit, karena menurut Mudgalapurana, dua penjelmaan Ganesa yang berbeda memakai nama yang diambil dari Lambodara yang berarti perut buncit, atau secara harifah perut bergelanjutan dan Mahodara (perut besar).

Menurut Ganesapurana, Ganesa juga digambarkan melilitkan ular Basuki dilehernya. Penggambaran lain tentang ular meliputi kegunaannya sebagai benang suci yang dililitkan melingkari perut sebagai sabuk, dipegang ditangan, dililitkan di pergelangan kaki, atau dipakai sebagai mahkota. Pada bagian dahi Ganesa kemungkinan ada mata ketiga atau simbol sekte Siwa (Sanskrta: tilaka), yang berupa tiga garis mendatar. Ganesapurana mengatakan bahwa tanda tilaka sama saja dengan bulan sabit pada dahi kepala. Wujud tertentu dari Ganesa yang disebut Bhalacandra "bulan didahi" memasukan unsurpenggambaran tersebut.
Sebuah lukisan bergaya Tajore, menampilkan Ganesa yang sedang mengendarai wahananya, yaitu tikus. Dibelakangnya tampak seorang pelayan yang setia menemaninya. Citra Ganesa pada mulanya tidak disertai dengan wahana (tunggangan). Pada delapan penjelmaan Ganesa yang dinyatakan dalam Mudgalapurana, Ganesa lima kali menggunakan tikus dan lima penjelmaannya menggunakan singa saat menjelma sebagai Wakratunda, seekor merak saat menjelma sebagai Wikata, dan menggunakan naga dalam penjelamaannya sebagai Wignaraja. Pada empat penjelamaan Ganesa yang terdaftar dalam Ganesapurana, Mohotkata menunggai singa, Mayureswara menunggangi merak, Dumraketu menunggangi kuda, dan Gajanana mengunggangi tikus (Satria, 2015 : 31-36).

\section{3) Pemujaan Dewa Ganesa}

Ganesa banyak dipuja saat acara kerohanian mauupun kegiatan sehari-hari, khususnya saat mulai berniaga seperti membeli kendaraan atau mulai bisnis. K.N. Somayaji berkata "jarang ada rumah (Hindu di India) yang tidak memiliki arca Ganesa (disebut juga Ganapati). Ganapati, sebagai Dewa yang termasyhur di India, dipuja oleh hampir seluruh kasta dan di seluruh penjuru negara". Pemujanya percaya bila Ganesa dibuat senang, ia akan memberi kesuksesan, kemakmuran, dan perlindungan terhadap bencana.

Ganesa bukan dewa bagi sekte tertentu, dan umat Hindu seluruh denominasi memanggil namanya saat memulai persembahyangan, memulai usaha yang penting, dan upacara keagamaan. Penari dan musisi, khususnya di India selatan memulai pertunjukan seni seperti misalnya tari Bharatanatyam dengan lebih dulu memuja Ganesa. Mantra-mantra seperti misalnya Om Shri Ganeshaya namah (Om, hormat pada Hyang Ganesa yang mahsyurmulia) seringkali dipakai salah satu mantra paling terkenal yang diasosiasikan dengan Ganesa adalah Om Gam Ganataye namah.

Ganesa dipuja secara luas sebagai "dewa bagi semua orang". Dalam tempat suci Hindu, Ganesa dapat diuraikan beraneka macam : sebagai parswadewata atau dewa bawahan; sebagai dewa yang erat dengan dewa utama atau pariwaradewata; atau sebagai dewa utama disebuah kuil pradhana, dijamu bagaikan dewa 
tertinggi di antara dewa-dewi Hindu.

Sebagai dewa keluar-masuk, Ganesa banyak ditempatkan di pintu gerbang kuil Hindu untuk menghalau hal-hal buruk, yang sama dengan perannya sebagai penjaga pintu rumah Parwati. T.A. Gopinatha berkata, "setiap desa, meskipun desa kecil, memiliki citra Wigneswara-nya sendiri denganatau tanpa kuil menempatkannya. Di jalan masuk menuju desa atau sebuah benteng, di bawah pohon bodhi dalam sebuah relung, di kuil Wisnu maupun Siwa dan juga pada bangunan suci yang khususnya dibangun dalam kuil Siwa; figur Wigneswara kelihatan tak berubah-ubah." Kuil Ganesa juga dibangun di luar India, termasuk Asia tenggara, Nepal, dan di beberapa negara barat, termasuk di Indonesia, khususnya di Bali (Satria, 2015 : 43-46)..

Sosok Dewa Ganesa di Bali lebih dikenal dan dipuja dalam konteks sebagai Dewa Ilmu Pengetahuan dan Kebijaksanaan sekaligus selaku Dewa Penghancur segala rintangan atau halangan. Sebagai Dewa Ilmu Pengetahuan dan Kebijaksanaan, keberadaannya dihadirkan melalui wujud Arca pada lembaga-lembaga pendidikan (sekolah atau perguruan tinggi), sedangkan selaku penghancur segala rintangan dan halangan, sosok magis Dewa Ganesa yang berfungsi sebagai pelindung dihadirkan, tepatnya ditempatkan dalam bentuk Arca pada bagian depan pintu masuk rumah, dan juga Pura, atau pada bagian depan setelah masuk pagar (panyengker). Lebih spesifik lagi figur Dewa Ganesa ini juga seringkali disthanakan pada bangunan suci (palinggih) Pura.

\subsection{Dewa Ganesa sebagai Simbol Agama}

Meskipun secara kasat mata, simbol-simbol agama adalah fakta kebudayaan, karena wujudnya dapat berbentuk benda-benda dan juga non benda. Tetapi agama (religi) bukanlah kebudayaan, sebab berada dalam tataran abstrak (bathin) yang inti dan sifatnya berhubungan dengan kepercayaan/keyakinan (sradha). Manifestasi sraddha agar benar-benar tampak nyata itulah sebagai cara-cara menjalankan agama, yang diantaranya dapat melahirkan simbol-simbol (Artadi, 2011 : 3536).

Melalui bukunya "Kunci-kunci Metodologis dalam Studi Simbolisme Kegamaan", Eliade (2000 : 184) menyatakan bahwa kunci pertama untuk memahami simbol-simbol keagamaan adalah bagaimana agar dunia "berbicara" atau "mengungkapkan diri" melalui simbol-simbol, dan bukan dalam bahasa utilitarian atau objektif. Simbol-simbol bukan sekedar cerminan realitas objektif, ia mengungkapkan sesuatu yang lebih pokok dan lebih mendasar. Begitu pula dengan simbol-simbol dalam agama Hindu dengan berbagai bentuk, wujud, nama dan fungsinya adalah mengandung arti untuk medekatkan umat kepada yang dipuja, yakni Tuhan Yang Maha Esa, manifestasi-Nya, para Devata, RohRoh para Rsi, dan Roh leluhur yang telah disucikan sesuai dengan ajaran Hindu (PHDI, 2013 : 67). Ini berarti sosok Dewa Ganesa adalah sebagai salah satu simbol identitas agama Hindu.

Berdasarkan hal itru, sudah saatnya khalayak umum, khususnya para pelaku dunia pariwisata untuk mengetahui, memahami dan diharapkan dapat menjadikannya sebagai pedoman tentang suatu "benda" yang dapat dikatakan sebagai benda budaya semata, atau merupakan hasil ekspresi budaya rohani bernilai sakral yang berfungsi sebagai simbol agama (Hindu). Secara estetika, seperti halnya sosok Dewa Ganesa yang telah diwujudkan dalam bentuk patung/arca, memang tampak mempunyai keunikan dan spesifikasi dari segi bentuk, dan rupa atau tampilannya yang eksotik, sehingga seringkali dinilai sebagai benda hasil karya budaya belaka, kemudian didayagunakan oleh pelaku pariwisata sebatas sebagai benda hasil kreasi seni bernilai ekonomi, lalu tanpa merasa berdosa dikomersilkan alias diperjualbelikan sebagaimana lazimnya barang komoditi lainnya.

\subsection{Dewa Ganesa sebagai Objek Tattoo}

Fenomena komodifikasi benda-benda bernilai keagamaan (suci/sakral) sepertinya sudah lumrah dalam industri pariwisata di Bali. Mulai dari pemanfaatan Pura yang adalah tempat suci umat Hindu sebagai objek wisata, pengemasan upacara yadnya sebagai paket wisata, pentas tari sakral (wali) sebagai tontonan para turis, termasuk pemanfaatan simbolsimbol suci Hindu dengan beraneka rupa, jenis dan bentuknya sebagai komoditi untuk memenuhi selera wisatawan. Satu diantaranya adalah dengan menjadikan sosok suci dan sakral Dewa Ganesa sebagai objek Tattoo pada media tubuh manusia.

Jika dicermati, di berbagai tempat wisata, 
seperti Kuta, Nusa Dua, Sanur, Candi Dasa, termasuk juga di Ubud sebagai destinasi wisatawan nusantara berkelas internasional, menunjukkan fakta adanya geliat dan gairah usaha Tattoo yang ternyata menjanjikan keuntungan lumayan. Sebagai kawasan pariwisata global/internasional, di tempattempat sebagaimana disebut di atas dijumpai puluhan bahkan ratusan usaha Tattoo, baik yang dikelola dan didanai pengusaha lokal, maupun luar Bali.

Andai saja usaha Tattoo yang kian tumbuh berkembang produktif itu mengambil objek diluar simbol suci/sakral Hindu mungkin saja hal itu dianggap sebagai sebuah kelaziman, biasa, lumrah dan tidak masalah. Namun ketika usaha Tattoo tersebut sudah mulai memanfaatkan simbol suci/sakral Hindu dalam wujud Dewa, manifestasi Tuhan, khususnya lagi Dewa Ganesa sebagai objek Tattoo, tentu tidak bisa dipandang remeh. Bagi umat Hindu, memindahkan sosok Ganesa pada media batu, logam atau kayu sebagai arca atau relief, pada kain sebagai kober (bendera) atau rerajahan (kaligrafi) jelas sebagai hal biasa, bisa diterima dan sudah menjadi bagian dari uparengga (sarana/prasarana) kelengkapan upacara/ upakara.

Akan tetapi ketika sosok Dewa Ganesa yang dipuja harus didegradasi nilai kesucian/ kesakralannya, lalu dipindahkan sebagai objek Tattoo pada media tubuh manusia (laki/

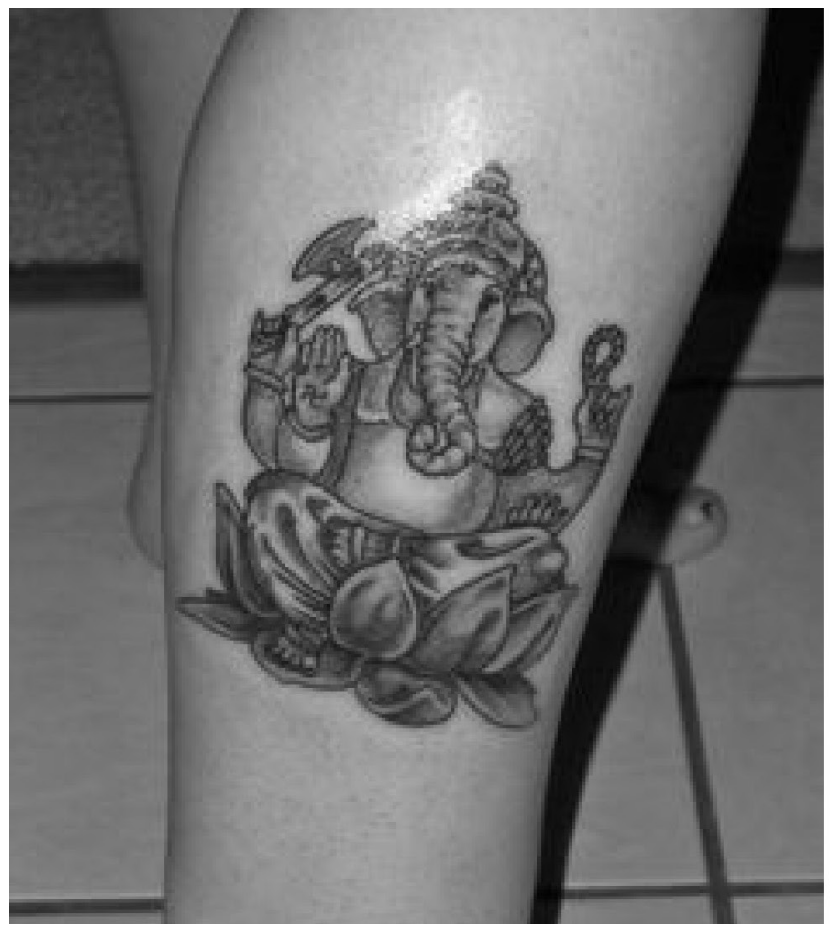

perempuan), bahkan dengan penempatan pada posisi bagian tubuh yang tidak etis hingga ke lekuk organ vital dan sensual, tentu patut dipertanyakan bahkan wajib dipersoalkan tanggungjawab moralnya. Sebab penempatan sosok Dewa Ganesa pada media tubuh merupakan bentuk komodifikasi yang berakibat terjadinya desakralisasi atau profanisasi, bahkan bisa dianggap sebagai tindakan pelecehan, penistaan atau penodaan terhadap simbol suci Hindu.

Bagi pemilik usaha Tattoo, bisa saja berdalih bahwa apa yang dilakukan itu sebagai bentuk menangkap peluang bisnis di kalangan turis, meski harus mengalahkan landasan etis, filosofis dan teologis dari sosok Dewa Ganesa, dengan memanfaatkan simbol suci Hindu itu sebagai objek komoditi. Begitupun dari para pelaku atau praktisi Tattoo, acapkali mengatakan usahanya itu sebagai bentuk penyaluran hobi yang sekaligus mendatangkan keuntungan finansial. Berbeda halnya jika umat Hindu diminta tanggapannya, yang secara keimanan (sraddha) meyakini sosok Ganesa sebagai putra Dewa Siwa, manifestasi Tuhan (Hyang Widhi) sebagai pelebur (pamralina), jelas akan merasa "terluka" perasaan bhaktinya melihat sosok Dewa yang dipujanya digambar/dilukis pada bagian tubuh manusia yang tidak etis, seperti pada bagian kaki, paha, berdekatan dengan pantat atau bahkan bersinggungan dengan alat vital yang sensual, seperti pada gambar berikut :

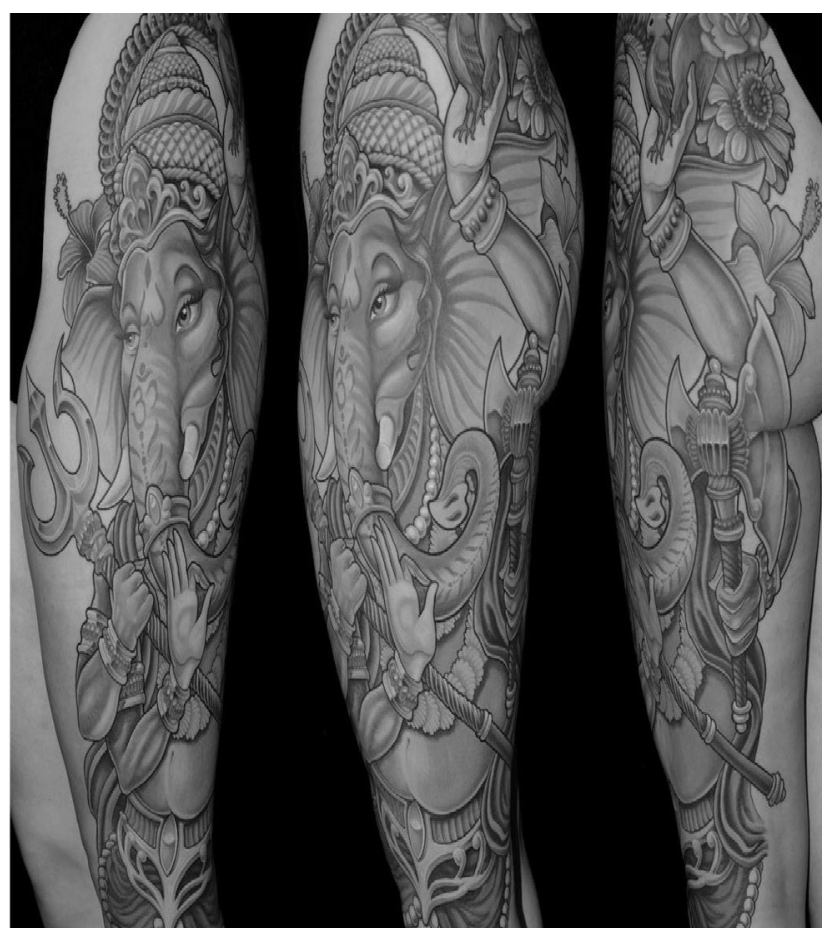




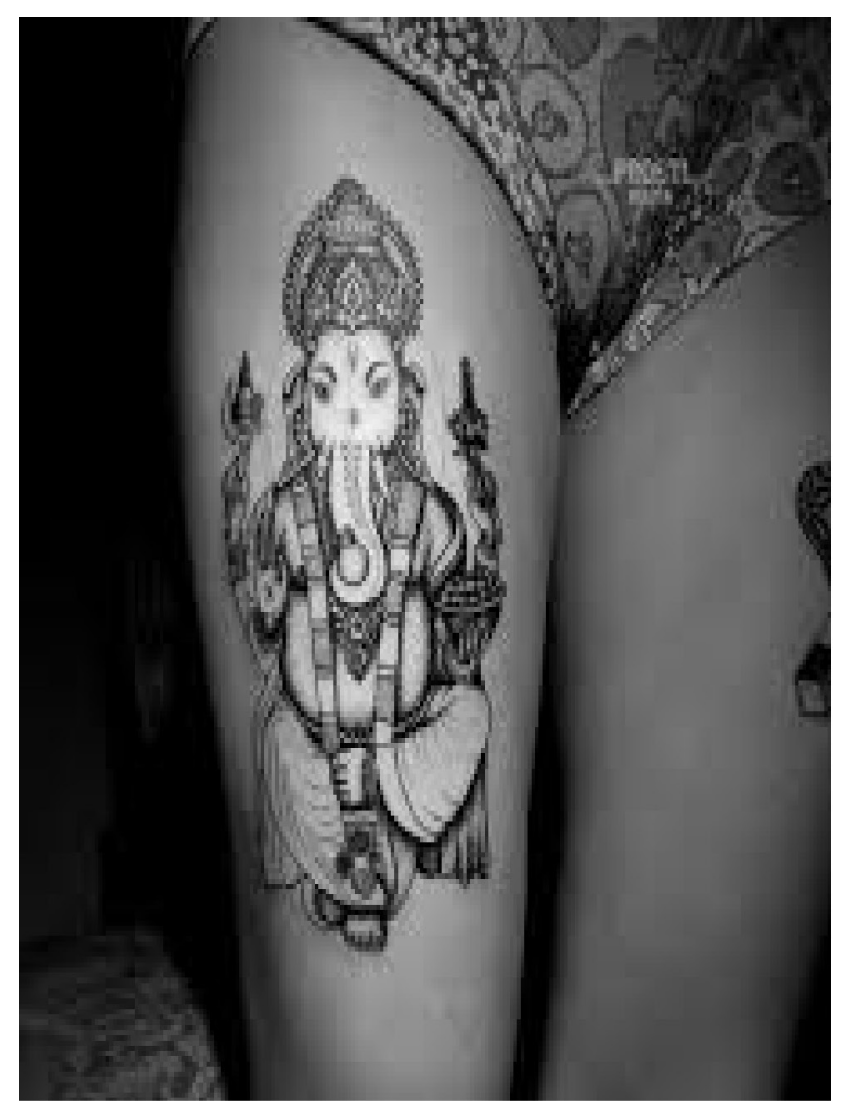

\subsection{Tattoo Ganesa sebagai Tatu bagi Umat Hindu}

Tumbuh berkembangnya usaha Tattoo dalam gairah industri pariwisata di Bali, dapat dicermati sebagai fenomena :

\section{1) Berkuasanya Ideologi Pasar}

Ideologi merupakan faktor penting bagi penggerak tindakan manusia, bahwa manusia bertindak, berbuat atau melakukan sesuatu tidak lepas bahkan sangat bergantung pada ide atau gagasannya. Jika dikaitkan dengan kecenderungan pemikiran pelaku pariwisata menyeret ranah agama melalui komodifikasi simbol-simbol sucinya, inilah yang oleh Atmaja (2006 : 122) disebut sebagai merasuknya pengaruh ideologi pasar. Hakikat ideologi pasar adalah menempatkan pasar sebagai tempat sangat penting bagi pemenuhan segala keinginan dan kebutuhan manusia. Karena itu, pasar tak ubahnya seperti 'tempat suci' bagi ideologi pasar atau agama pasar. Bahwa hanya untuk kebutuhan upacara yadnyapun, sekarang ini sudah berorientasi pada pasar (Geriya, 2008 : 103), tentunya dengan berbasis pada "moneytheisme" - keuangan yang maha kuasa.

Perihal kekuasaan uang itu sendiri, Simmel (dalam Ritzer, 2007 : 45) melalui Philosophy of
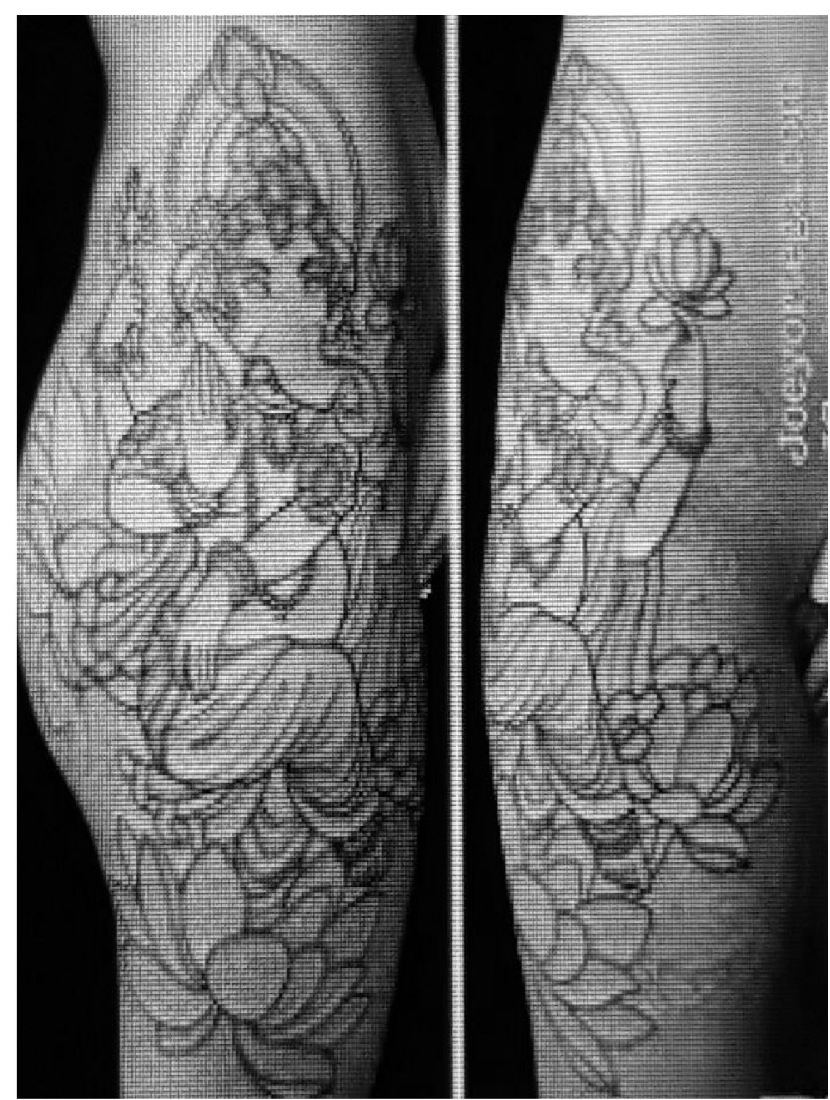

Money menguatkan pandangan di atas bahwa ekonomi masyarakat modern dengan seluruh komponennya (termasuk ekonomi uang) akan terus berkembang, dan ketika semakin berkembang maka arti penting (peran) individu dengan nilai kemanusiaannya cenderung menurun bahkan merosot, tergantikan oleh nilai material-finansial yang perputarannya berporos pada keberadaan atau kepemilikan modal kapital -- lagi-lagi uang.

\section{2) Bergesernya Konsep Bhakti Menjadi "Bati"}

Bhakti adalah kata kunci bagi umat Hindu dalam merealisasikan keyakinan (sraddha) kehadapan Hyang Widhi, beserta manifestasinya. Akan tetapi ketika konsep bhakti sudah mulai terpengaruh, bahkan tergerus oleh ideologi pasar berbasis "moneytheisme" tentunya tak dapat dihindari terjadinya pergeseran dari konsep bhakti menjadi "bati". Dicirikan oleh tumbuhnya sikap pamrih untuk mendapatkan keuntungan material-finansial. Konsekuensinya, apa yang sebelumnya dipegang teguh sebagai bagian bhakti murni (parabhakti) dengan hanya memikirkan dan mrenungkan Tuhan semata, kini rasa bhaktinya telah mengalami ditransformasi menjadi kesempatan ngalih bati 
(aparabhakti). Caranya dengan memanfaatkan simbol-simbol suci agama Hindu, dalam bentuk komodifikasi, termasuk terhadap simbol suci/ sakral Dewa Ganesa sebagai objek Tattoo pada tubuh manusia, dengan harapan mendapatkan keuntungan material-finansial.

Mengadopsi pandangan Sugiharto (dalam Adlin, 2007 : 5) fenomena di atas dapat disebut sebagai situasi manusia modern atau zaman now. Paradigma utamanya adalah memanipulasi tubuh/materi dengan lebih mengedepankan bagaimana bisa "memiliki" materi lebih banyak, bukan bagaimana "menjadi" orang yang lebih bermakna. Kenyataannya kini, kebanyakan orang di tengah peradaban modern kontemporer yang kian sekuler, nyaris tidak menyentuh persoalan menjadikan diri semakin religius/ spiritualis, tetpai lebih mengembangkan cara hidup bergaya materialis, konsumeris dan hedonis. Sehingga yang tumbuh berkembang sebagai modal rohaniah, bukannya aktivitas ritual bergerak meningkat menjadi spiritual, justru berubah menjadi gairah "spirit-jual", suatu kondisi dimana umat menggairahkan semangat "jual-beli". Diliputi semangat "kebatinan" dengan menjual segala potensi ritual dengan simbol-simbol suci/sakralnya demi meraup keuntungan di tengah persaingan industri pariwisata.

Bentuk aktivitas pariwisata dengan "mengorbankan" media simbol ritual seperti halnya sosok Dewa Ganesa yang amat disucikan sekaligus dipuja inilah yang dapat dikatakan masuk ke dalam katagori Rajasik, karena didorong oleh motif keinginan mendapatkan pahala bati. Hal ini dengan jelas dinyatakan di kitab suci Bhagawadgita, XVIII, 34 dan 38 :

"Yaya tu dharmakamarthan dhritya dharayate 'Arjuna, prasangena phalakanksi dhritih sa partha rajasi"; "Wisayedriya samyogad yat tad agre 'mritopanam, pariname wisam iwa tat sukham rajas am smritam"
Maksudnya :

"Tetapi O Arjuna, dengan mana seseorang berpegang pada kewajiban, kesenangan, kekayaan, menginginkan akan pahala sebagai konsekuensi mengharapkan pahala, keteguhan hati ini adalah rajasa ; " Kebahahagiaan yang timbul dari hubungan antara indria dengan objek duniawi yang pada mulanya bagaikan amrita tetapi akhirnya jadi racun, kebahagiaan begini dicatat sebagai rajasa" (Pudja, 1981 : 393, 395).

\section{PENUTUP}

Bali memang dikenal bahkan terkenal melalui dunia pariwisata hingga mengglobal. Akan tetapi, pariwisata bukanlah segala-galanya, hingga harus mengorbankan simbol-simbol suci/sakral seperti halnya sosok Dewa Ganesa sebagai objek Tattoo. Tindakan demikian sama saja dengan membuat tatu (luka) batiniah bagi umat Hindu yang begitu menjungjung tinggi Dewa Pujaannya, namun faktanya oleh palaku pariwisata dijadikan sebagai komoditi melalui praktik komodifikasi. Tindakan komodifikasi tersebut, sejatinya sama saja dengan mendegradasi nilai kesucian/kesakralan bahkan keagungan dan kemuliaannya sehingga terjadilah apa yang disebut desakralisasi atau profanisasi.

Sudah saatnya, dinamika dunia industri pariwisata digerakkan dengan tetap berjalan pada koridor kepatutan etik, dan normatif. Tentunya dengan tidak mendegradasi tatanan nilai etis, estetis, filosofis dan teologis yang mendasarinya. Pariwisata tetap didorong dan dipersilakan berkembang dengan pesat mencapai kemajuan, tetapi dengan tanpa berkhianat pada amanat yang direfleksikan lewat simbol-simbol suci agama Hindu. Hanya dengan begitu, eksistensi Bali dengan karakter sosio-magis-religiusnya bisa dipertahankan keajegannya, yang sama artinya melanggengkan kelangsungan gemerlap dunia pariwisata yang memang sangat tergantung pada "roh" Hindu yang menjiwai adat dan budaya masyarakat Bali. 


\section{DAFTAR PUSTAKA}

Adlin, Alfathri . 2007. Spiritualitas dan Realitas Kebudayaan Kontemporer. Yogyakarta \& Bandung. Jalasutra.

Artadi, I Ketut. 2011. Kebudayaan Spiritualitas. Denpasar : Pustaka Bali Post.

Atmadja, Nengah Bawa 2006. "Pemanfaatan Modal Budaya dan Modal Tubuh Menjadi Modal Ekonomi Berbentuk Hiburan Seks Melalui Rangsangan Mata (Kasus Joged Bumbung Ngebor di Buleleng, Bali), Singaraja.

Eliade, Mircea. 2000. Kunci-Kunci Metodologis dalam Studi Simbolisme Keagamaan, dalam Metodologi Studi Agama, Editor Ahmad Norma Permata Pustaka Pelajar, Yogyakarta.

Geriya, I Wayan. 2008. Transformasi Kebudayaan Bali Memasuki Abad XXI. Surabaya : Paramita.

Parisada Hindu Dharma Indonesia. 2013. Swastikarana, Pedoman Ajaran Hindu Dharma.Denpasar : PT Mabhakti.

Pudja, G. 1981. Bhagawadgita (Pancama Weda). Jakarta: Mayasari.

Ritzer, George, Douglas J. Goodman. 2007. Teori Sosiologi Modern, (Edisi Keenam). (Alih Bahasa: Alimandan). Jakarta. Kencana.

Satria, Wiras. 2015. Sejarah Paradewa. Yogyakarta : Lukita

Widana, I Gusti Ketut. 2012. Penjor Lebay. Denpasar : Pustaka Bali Post. 